\title{
Google and the Trans-Atlantic Antitrust Abyss
}

Bergqvist, Christian; Rubin, Jonathan

Published in:

Concurrences

Publication date:

2019

Document version

Publisher's PDF, also known as Version of record

Citation for published version (APA):

Bergqvist, C., \& Rubin, J. (2019). Google and the Trans-Atlantic Antitrust Abyss. Concurrences, sep/2019(3). 


\section{Concurrences}

REVUE DES DROITS DE LA CONCURRENCE | COMPETITION LAW REVIEW

\section{Google and the trans-Atlantic antitrust abyss}

Article 1 Concurrences N N $^{3}-2019$

www.concurrences.com

Christian Bergqvist

cbe@jur.ku.dk

Associate Professor

University of Copenhagen

Jonathan Rubin

jrubin@moginrubin.com

Partner

MoginRubin, Washington, D.C. 


\section{Christian Bergqvist \\ cbe@jur.ku.dk}

Associate Professor

University of Copenhagen

\section{Jonathan Rubin jrubin@moginrubin.com}

Partner

MoginRubin, Washington, D.C.

\section{Google and the trans-Atlantic antitrust abyss}

1. In June 2017, DG COMP, the competition arm of the European Commission and Europe's principal antitrust enforcer, finally concluded its investigation into Google's search business, identifying a clear and aggravated infringement of Article 102, which prohibits the abuse of a dominant position. ${ }^{1}$ After an eight-year investigation and three attempts at settlement, the Commission imposed a EUR 2.42 billion fine, thereby doubling the ceiling on fines against individual firms. The Google Search (Shopping) decision also ordered Google to remedy the abuse within 90 days or face daily penalties of up to $5 \%$ of global group turnover. ${ }^{2}$ As the search bias issue was only one of six charges levied against the firm, the June 2017 decision were followed by a EUR 4.34 billion fine on Android $^{3}$ in 2018 and a EUR 1.49 billion fine on AdSense ${ }^{4}$ in 2019, with further cases pending. ${ }^{5}$ In stark contrast to the outcome in the EU Google Search case, the U.S. Federal Trade Commission (FTC) in 2013 declined to pursue charges against Google for the same alleged conduct. ${ }^{6}$ While the decision may have been a close call, it stands as a unanimous decision by all five Commissioners not to attempt to build a case against Google search and in principle acquitting the firm of wrongdoing under the U.S. antitrust laws.

2. Because the complaints against Google search to the antitrust authorities in the EU and the U.S. were more or less identical, the two competition authorities investigated the same alleged anticompetitive conduct. It is useful, therefore, to compare and explain the proceedings and their opposite outcomes. One can contemplate, for example, whether the FTC's decision to stand down represents a better balancing of interests in the application of antitrust law than the approach taken in the EU, with its arguably draconian outcome, and whether a U.S. court would have sided with the government had the FTC chosen to pursue a case against Google. Although this exercise involves second guessing that requires caution, it provides the context for a direct comparison of U.S. and EU antitrust principles and can shed light on whether any legal elements embedded in the two jurisdictions create different outcomes in otherwise identical cases.

3. The article proceeds in four parts. First, we offer some general background remarks on Google and the Google services implicated in the two proceedings. In the second part we examine the EU Google Search decision and its legal foundations. No comments are offered on the Android and AdSense Decisions as neither have been published. Next, we analyze the FTC's rationale for closing its investigation into Google search. Finally, we compare the two legal regimes

\footnotetext{
1 Case AT.39.740 - Google Search (Shopping).

2 See Case AT.39.740 - Google Search (Shopping), Recital 700 for a summary of the obligations.

3 Case 40.099-Google Android.

4 Case 40.411 - Google Search (AdSense).

5 Neither have been published and no analysis will be attempted on these.

6 Statement of the Federal Trade Commission Regarding Google's Search Practices, In re Google Inc., FTC File Number 111-0163 January 3, 2013.
} 
by analyzing the likely outcome of hypothetical litigation against Google had the FTC decided to challenge the conduct described by the evidence adduced in the EU proceeding. While necessarily speculative, we think this exercise represents a reasonable approach to illustrating the merits of the antitrust case against Google search in the wider context of the doctrinal and procedural features of the EU and U.S. antitrust enforcement regimes. In conclusion, we tentatively identify the features and approach of each regime that may account for the dramatically different outcomes on the two sides of the Atlantic.

4. To the extent documentation was available, we found the legal considerations taken by the two competition authorities to have been strikingly similar, which only obscures the reasons for the opposite outcomes. We ultimately conclude that, in at least this instance, the EU authorities implemented a broader legal standard than did the FTC, which appears to have struggled with applying a net consumer welfare standard in the hightech Internet search market. Since DG COMP's decision did not expressly state the legal standard to be applied to the challenged conduct, it can be inferred that the EU implemented some version of the ordoliberal enforcement approach, by which governmental intervention is appropriate to protect ("order") the process of market competition and does not depend on a showing that a particular form of allegedly anticompetitive conduct is likely to generate a net negative welfare effect. Under such a standard, a reduction in consumer choice could be sufficient to warrant condemnation of the conduct.

\section{The Google brand and services offered}

5. Google, whose parent corporation was renamed Alphabet Inc. in 2016, was established in 1998 as a two-sided platform that allows users to search the Internet at no charge while offering advertisers the privilege of appearing in or near the search results or on web pages listed in those results. ${ }^{7}$ Google interacts with the users by providing generic search results ${ }^{8}$ in response to the entry of an inquiry. ${ }^{9}$ The results have been generated by progressively more advanced search algorithms that over the years has evolved to include an analysis of users'

\footnotetext{
7 A two-sided platform should not be confused with a two-sided market, see S. Broos and J. Marcos Ramos, Google, Google Shopping and Amazon: The Importance of Competing Business Models and Two-Sided Intermediaries in Defining Relevant Markets (November 27, 2015). The Antitrust Bulletin, Vol. 62, Issue 2 (2017). Available at SSRN: https://ssrn.com/abstract $=2696045$.

8 Sometimes also referred to as natural search result or organic search result cf. case AT.39.740 - Google Search (Shopping), Recital 10, note 8. In accordance with DG COMP preference generic will be used in this paper.

9 Sometimes referred to as Search Engine Result Pages (SERF). Moreover, the delivery of generic search results involves three automated processes: crawling, indexing and serving cf. Case AT.39.740 - Google Search (Shopping), Recital 15. For a walkthrough of search engines, their functionality and economics, see M. Herz (2014). Google Search and the Law on Dominance in the EU: An Assessment of the Compatibility of Current Methodology with Multi-Sided Platforms in Online Search. SSRN, pp. 1-20.
}

choices, referred to as "click-through rates," 10 which feedback into the algorithm to generate better and more precise results. In addition to the generic, unsponsored results, additional results are provided today in the form of (i) sponsored ads and links normally displayed above the generic results, and, (ii) commercial products, services, and information, normally provided in separate boxes. Thus, rather than a single response to an inquiry, Google now provides three separate sets of search results, ${ }^{11}$ two of which lead to Google-affiliated services, in addition to the generic search results. ${ }^{12}$ On account of this blend of search results, Google prefers to term it service "Universal" rather than what later will be referred to as "general and specialized" searches.

6. Google interacts with advertisers through its AdWords and AdSense services and certain specialized Google services. AdWords provides a platform for advertisers to bid on keywords for placement in "sponsored" search results returned when the keyword is used in the search string. Advertisers pay Google each time a user clicks on one of their links. AdSense extends AdWords to display ads on other websites and allows for elaborate content, including text, images, and video and the management of advertisements across the Internet.

7. Although Internet search is free, it benefits Google by providing the company with information about the user that contributes to developing and maintaining Google's proprietary algorithms and its store of consumer data, which can be profitably exploited by advertisers. As for monetary income, AdWords accounts for most of Google's search revenue, while AdSense generates somewhat less revenue. ${ }^{13}$ Additional services, often with dedicated websites, were launched starting in 2001, including Google Images (2001), Froogle (2002), later re-branded as Google Product Search (2007) and eventually Google Shopping (2012), Google Maps (2004), and Google Flights (2011), ${ }^{14}$ offering images, shopping, maps and travel services. Such services with a narrow focus on a specific subject matter are commonly distinguished from services that offer a general search across the entire Internet, with the former frequently referred to as specialized (vertical) search and the latter as general (horizontal) search. ${ }^{15}$ While convergence in

10 FTC Memorandum dated August 8, 2012 on Google Inc, File No. 111-0163, p. 14.

11 In reality Google might today provide more than three searches as new info-boxes appear to have been incorporated and blended with the generic results.

12 See, e.g., case AT.39.740 - Google Search (Shopping), Recitals 8-37 for more about Google search engines and the display of the different search results.

13 Case AT.39.740 - Google Search (Shopping), Recitals 7 and 296, referring to Alphabet's US Securities and Exchange Commission, Form 10-K, Annual Report for the fiscal year ending 31 December 2016

14 The product description is taken from the outline provided in case AT.39.740 - Google Search (Shopping), Recitals 27-31, that presents additional Google services. For further on the evolution of Internet searches see M. A. Salinger \& R. J. Levinson, Economics and the FTC's Google Investigation, 46 Rev. Indus. Org. 25 (2015), pp. 32-42 and FTC Memorandum dated August 8, 2012 on Google Inc, File No. 111-0163.

15 In addition to specialized search and vertical search, the term universal search, which blends these, is also used, cf. case AT.39.740 - Google Search (Shopping), Recital 10, note 9. However, it appears that DG COMP uses universal search as an alternative for vertical search rather than the blended search. 
the longer run is plausible, these two services provide in principle two competing ways of accessing information available on the Internet. ${ }^{16}$ Initially, the emergence of specialized search had little effect on Google's business model, because merchants did not pay to be listed in Froogle or Google Product Search, which were monetized through advertising. In 2012 Google modified its business model by instituting a charge to merchants for each click on their product in what was relabeled as Google Shopping.

8. In 2007, Google included a new feature by which general search results were returned with additional information, which included a "shopping function," called Product Universal, later renamed Commercial Unit and then Shopping Unit. These products display search results from a Google-affiliated specialized search engine, such as Google Shopping, in dedicated boxes, ${ }^{17}$ accompanied by pictures and essential information, such as product prices. ${ }^{18}$ By extracting relevant content from specialized Google services and displaying it in a separate box alongside general search results, Google Search has added functionality that allows its general search services to substitute for specialized search engines, which motivates Google to brand its service as Universal Search, because all the categories of results are provided in response to a single query. More specifically, Google provides three categories of search results, a set of relevant ads, content in the box, and the generic search results. Only the first category of results generates direct revenue (through AdWords, which remains Google's predominant source of income), although its specialized search services and the Shopping Unit also provide significant indirect revenue. ${ }^{19}$

9. Indications of self-favoritism and bias in search results emerged as early as $2007,{ }^{20}$ leading to the perception that Google did not always provide the most relevant reply to a search inquiry. Ultimately, these perceptions resulted in formal complaints to the U.S. and EU antitrust authorities. ${ }^{21}$ Notably, the U.S. investigation examined Google's policies relating to all services placed in the box,

16 See case AT.39.740 - Google Search (Shopping), Recitals 166-177 for further on the differences and M. A. Salinger \& R. J. Levinson, Economics and the FTC's Google Investigation, 46 Rev. Indus. Org. 25 (2015), pp. 32-42 for an outline of the development of Internet searches, including Google first specialized searches.

17 It's unclear whether Google operates one or several separate info boxes. The labels OneBox and Knowledge Panels are both used, suggesting the appearance of different boxes and functionalities. For simplicity, however, the paper will assume that there is only one box that differs in content depending upon the nature of the search query.

18 In the process of renaming the services Google also adjusted it function as the Shopping Unit, in contrast to the earlier Product Universal lead users directly to the pages of Google' merchant partner, where the user can purchase the products cf. case AT.39.740 - Google Search (Shopping), Recital 32.

19 The issue of profitability of different Google products, and how Google lacks an incentive to attempt a foreclosure of dependent or downstream markets, are often used to refute any search bias as Google lack incentive to pursue such strategy. This paper offers no opinion on the matter.

20 Letter from Senators Herb Kohl and Mike Lee to Jonathan D. Liebowitz, December 19, 2011, at p. 3 referring to a speech delivered by a Google executive.

21 Descriptions of the complainants and their grievances can be found at www.fairsearch.org and at www.searchneutrality.org. Moreover, complaints have been lodged in several other jurisdictions. However, this paper will limit itself to EU and US with a few references to a German and UK case. while the EU (initially) was more narrowly focused on favoritism toward Google Shopping. In further contrast to the EU, the FTC appears to have perceived the box and the concept of Universal search as improvements to Google's general search service, and therefore beneficial to consumers, a likely factor contributing to the different outcomes.

\section{The EU Google Search decision}

10. Despite meting out the largest fine in EU antitrust history, indicating that the European Commission must have considered Google's conduct to have been a clear and most grave competition law violation, the reasoning and analysis behind its 2017 Google Search decision is neither clear nor straightforward. The decision easily could have come out differently had the authorities given more weight to Google's defenses to the alleged wrongdoing, as did the FTC in the U.S. decision. There is reason to believe that initially they did so. On three occasions DG COMP attempted to close its proceeding with behavioral commitments by the accused violator. Nonetheless, the Commission ultimately decided to advance the case under a novel and untested theory of harm. It is unclear, therefore, whether the EU Courts will be receptive to the merits of the decision when called upon to review it. ${ }^{22}$ The outcome of the pending appeal, therefore, is not a foregone conclusion. The analysis of the EU Google Search decision starts with a review of the decision's operative parts followed by a dissection of its legal principles.

\section{A long, slow road from 2009 to 2017}

11. In November 2009, Foundem, a shopping and price comparison website, lodged a complaint with DG COMP over the results to search inquiries entered on www. google.com and corresponding national search services operated under the Google brand. ${ }^{23}$ The complaint alleged that rather than directing end-users to the most relevant Internet pages, the results were biased in favor of Google-affiliated offerings. For merchants appearing in both unpaid and paid search results, such behavior translated into a lower listing in the index of sites, resulting in a less favorable position on the list of results returned to end-users. Moreover, because end-users are reluctant to consider more than the first three to five links returned,$^{24}$ to appear below these levels is tantamount to not being displayed at all, which, according to Foundem,

\footnotetext{
22 The decision has been challenged as case T-612/17 - Google and Alphabet. O.J. 2017C 369, p. 37.

23 See press release from the Commission 30 November 2010 - IP /10/1624 - Antitrust: Commission probes allegations of antitrust violations by Google.
}

24 See case AT.39.740 - Google Search (Shopping), Recitals 453-457 and 535 . 
was how Google's conduct had injured them.$^{25}$ Of course, Google denied any wrongdoing, but in the course of 2010 additional complainants urging other grievances came forward, ${ }^{26}$ eventually emerging as additional substantive allegations. ${ }^{27}$ In addition to the alleged bias in search results, the complainants also alleged that Google (i) made use of unlicensed content from unaffiliated websites, a practice called "scraping," and, (ii) forced publishers and advertisers into exclusive use of Google's AdSense and AdWords services with the intent to foreclose rival platforms from the market for online search advertising.

12. Google quickly relented on the use of exclusive agreements, ${ }^{28}$ which allowed DG COMP to concentrate on the issues of search bias and scraping, although the latter more resembled an IP infringement than an antitrust violation. ${ }^{29}$ These efforts led to three rounds of settlement negotiations, each of which were successful from the perspective of Google and DG COMP, but all of which were rejected when the terms of the settlements were circulated for consultations. ${ }^{30}$ Thereafter, during 2014-15, DG COMP chose to pursue the case to a formal decision, ${ }^{31}$ supplemented with new objections regarding Android, Google's smartphone operating system. ${ }^{32}$ Although the Android matter is a separate proceeding, it involves some of the same concerns over self-dealing and Google's leveraging of economic power into adjacent markets that motivated the investigation into general search. Accordingly, the EU's approach in later proceedings is likely to rely on some of the same legal concepts and considerations as in the current case. ${ }^{33}$

25 Charles Arthur, Foundem accuses Google of using its power to favour own links, The Guardian 30 November 2010 and more recently Charles Duhigg The Case Against Google, New York Times 20 February 2018

26 See case AT.39.740 - Google Search (Shopping), Recitals 39-95, for outline of plaintiffs and other parties.

27 See memo from the Commission 25 April 2013 -Commission seeks feedback on commitments offered by Google to address competition concerns - questions and answers.

28 Google abandoned exclusivity, but DG COMP nonetheless issued a Statement of Objection (SO) in 2016 indicating an intention of reverting to the matter. See press release from the Commission 14 July 2016 - IP/16/2532 - Antitrust: Commission takes further steps in investigations alleging Google's comparison shopping and advertising-related practices breach EU rules.

29 There is an antitrust element to the scrapping allegations, as Google appears to have used the scraped content to improve the quality and user experience of Google service, and thus either strengthened its (potential) dominant position or leveraged this onto new markets and services.

30 Statement on the Google investigation by Commissioner Almunia 5 February 2014

31 Embedded in the decision also appears to have been a decision to focus on the Sopping Unit and Google specialized shopping service rather than Product Universal and all specialized services as initially and in the FTC investigation.

32 Case 40.099-Google Android. Delivered in July 2018. For further see press release from the Commission 18 July 2018 - IP/18/458 - Antitrust: commission fines google $€ 4.34$ billion for illegal practices regarding android mobile devices to strengthen dominance of Google's search engine.

33 For an analysis of the Android case, see P. F. Todd Out for the box: illegal tying and Google's suite of apps for the Android OS, European Competition Journal, 2017 13:1, 62-92; F. Etro \& C. Caffarra, On the economics of the Android case, European Competition Journal 2017, 13:2-3, pp. 282-313, and B. Edelman \& D. Geradin (2016) Android and competition law: exploring and assessing Google's practice in mobile, European Competition Journal, Vol. 12:2-3, pp. 159-194.

\section{The EU decision}

13. The proceedings came to a climax in June 2017, with the release of the EU's Google Search decision..$^{34}$ DG COMP identified an abuse of a dominant position and doled out a record fine of EUR 2.42 billion (USD 2.97 billion). Compared to the 518-page Intel ${ }^{35}$ decision in 2009 or the 302-page Microsoft $t^{36}$ decision in 2004, the Commission's 216-page decision in Google Search was relatively brief. To some extent, its brevity follows from DG COMP's focus on the search bias allegations and its deferral of the other charges for adjudication in separate proceedings. But its brevity is also a product of the vague theory of harm driving the case, which obviated the need for the Commission to explain how the evidence met the traditional legal standards for well-defined abuses. Google's claim that it was found liable in the EU under a novel and unprecedented "abusive leverage" standard devoid of clear precedential support is not entirely unfounded ${ }^{37}$ However, as we show below, it would be more accurate to claim the company was adjudged under an established standard, but where the case fell short of these requirements, with the ramification that DG COMP appeared to have been engaged in an attempt at redefining the case law rather than building upon it. ${ }^{38}$

14. The finding of abuse is based on the presence of two vertically linked markets, an upstream general search market dominated by Google and a specialized search market that is competitive. In the upstream market the dominant provider purportedly maliciously downgrades search results in order to favor its own interests in the competitive downstream market. ${ }^{39}$ The downgrading was accomplished by (i) submitting competing offerings only to the generic search ranking algorithm, and (ii) reserving the best positioning in the generic search results and the separate box for Google's own offerings. ${ }^{40}$ The decision stands for the proposition that these elements alone are sufficient to make out a claim for "abusive leveraging," thereby injecting a concept of abuse into Article 102 that encompasses self-favoritism as a violation, or perhaps an even more expansive interpretation.

\footnotetext{
34 Case AT.39.740 - Google Search (Shopping).

35 Case 37.990 - Intel.

36 Case $37.792-$ Microsoft

37 See case T-612/17 - Google and Alphabet. O.J. 2017C 369, p. 37, plea 5.
}

38 P. Akman, The Theory of Abuse in Google Search: A Positive and Normative Assessment Under EU Competition Law, J. L. Tech.\& Policy 2017, pp. 301-374, contemplates, but rejects, the ability to accommodate the behavior under a traditional standard of abuse.

39 The Commission stopped short of making an express finding of malice or intent, but Commissioner Vestager did state the following at a press conference to announce the decision: "We haven't found evidence of intent when it comes to demoting other rivals, but what we have seen in the evidence is the fact that the Google comparison shopping services, Google Shopping, has been given a better treatment, a significantly better treatment, by being placed up front no matter the result of the search query and the demotion of rivals. That combination is what we have concluded is the abuse of the dominant position." Press conference by Margrethe Vestager, European Commissioner for Competition on Google search (June 27, 2018), at 28:00, available at: http://ec.europa.eu/avservices/video/player.cfm?ref=I141016\&sitelang=en\&lg=INT.

40 See Recital 379. Pursuant to Recital 2,"The Decision establishes that the more favourable positioning and display by Google, in its general search results pages, of its own comparison shopping service compared to competing comparison shopping services (the 'Conduct') infringes Article 102.'This indicates that reserving a better position rather than downgrading competing offerings constitutes the abuse, see, e.g., Recital 2. But see, e.g., Recitals 342 and 344 , which point to the combination as abusive. 


\subsection{A tale of two (and an extra) markets, with links}

15. By definition, an abuse under Article 102 (and for the most part, a violation of the U.S. anti-monopolization law) requires the subject firm to be dominant in a relevant market. Such cases traditionally proceed from a comprehensive description and analysis of the market, the alleged conduct constituting the abuse, and the anticompetitive market effects alleged to follow. In this regard, the EU Google Search decision follows that tradition by identifying two product markets, both national in geographical scope, but implicitly also relying on a third. ${ }^{41}$ These are: ${ }^{42}$

- General search market, in which services offer searches across the entire Internet for whatever query is entered in the search engine. General searches can be distinguished from other online services, such as, ${ }^{43}$ (i) content sites, like newsgroups, newspaper and information repositories, such as Wikipedia, (ii) social media sites, such as Facebook and LinkedIn, and, (iii) specialized search engines, such as the travel site, www.kayak.com, which provides search results within a specific subject matter. Moreover, there is little or no differentiation between searches performed on stationary devices (personal computers and laptops) and mobile devices (smartphones and tablets). ${ }^{44}$

- Comparison shopping market, in which services offer searches for specific products or services and provide a means to compare products and prices directly on the platform without visiting a different, specialized website or by providing information and links to those sites. ${ }^{45}$ Comparison shopping services are distinct from: (i) online merchant and merchant platforms, such as Amazon and eBay, where consumers can actually purchase products, (ii) specialized search engines focusing on a single subject matter, (iii) online search advertising platforms, (iv) various other direct online retailers, and (v) offline comparison shopping tools, such as print catalog and television advertisements.

41 The markets are held to be national in scope largely for linguistic reasons, cf. Recitals 251-263.

42 See Recitals 154-263 for an outline of the two principal markets. For a critical analysis of the segmentation into two separate markets see S. Broos and J. Marcos Ramos, Google, Google Shopping and Amazon: The Importance of Competing Business Models and Two-Sided Intermediaries in Defining Relevant Markets (November 27, 2015). The Antitrust Bulletin, Vol. 62, Issue 2 (2017). Available at SSRN: https://ssrn.com/abstract=2696045.

43 See Recitals $161-190$

44 Nevertheless, in Recitals 325-330, DG COMP reverts to the matter, rebutting market segmentation that would call into question Google's position as dominant.

45 Recitals $191-250$.
- Shopping site market, consisting of online merchants and merchant platforms that sell products and services directly to consumers, which may include specialized search engines that focus on shopping. Without expressly describing it, this market plays a tacit role in the decision, because DG COMP suggested that links appearing in Google's comparison shopping service are sourced from the shopping site market rather than from an actual search across the Internet, and preferentially display links to Google's shopping site. ${ }^{46}$ Moreover, Google frequently alludes to intense competitive pressure on its comparison shopping service from players in the shopping site market, such as Amazon. ${ }^{47}$ Thus, both DG COMP and Google blur the lines between the market definitions by referring to the competitive influence of the participants in the shopping site market.

16. There is a connection between the general search market and the comparison shopping market, ${ }^{48}$ because links to the latter may be provided in reply to a search on the former. ${ }^{49}$ Thus, Google's general search serves as an intermediary between consumers and online retailers, merchants, and merchant platforms, including Google's own shopping sites, by providing a comparison of available products and services across retailers and platforms in response to a general search query. By contrast, shopping sites can substitute for both general search and specialized search or serve as an intermediary to the latter. ${ }^{50}$ This holds as long as comparison shopping services either undertake an actual search across the Internet or utilize information already available from specialized (vertical) search engines. Regrettably, DG COMP was silent on this point by defining only the first two markets, followed up with the conclusion that the general search market is dominated by Google, with a market share estimated above 90 percent in most EU countries. ${ }^{51}$ Google is present in the comparison shopping market with Google Shopping (not to be confused with the Shopping Unit), and its market position is unknown, although there appears to be no less than 361 alternative comparison shopping providers. ${ }^{52}$ By contrast, DG COMP exerts significant effort to explain how Google dominates the general

\footnotetext{
46 Recitals 29 and 411 .

47 Recitals $235-246$ and 590.

48 We leave for elsewhere the debate over whether traditional industrial organization concepts such as upstream/downstream and vertical distribution chains meaningfully can be applied to the services rendered by Google, as well as the extent to which the standards of abuse are influenced by doing so, since, presumably, such influence is possible.

49 See Recitals $540-541$ for a substantive analysis.

50 Recitals 220 and $610 \mathrm{c}$ indicate a perception among Google and merchant platforms of a vertical relationship between comparison shopping services and the later.

51 See Recital 282 for an outline of market shares across member states, and Recital 327 for a possible national segregation on mobile devices.

52 See Recital 241 referring to 361 competing comparison shopping services in the EEA identified by Google and Recital 370 for the identity of some of them. Recital 613 refers to 380 such services. It is unclear whether DG COMP accepts the numbers provided, but Recital 604 indicates some skepticism about the number.
} 
search market through strong network and bandwagon effects that entrench its near-monopoly position, but offers little about comparison shopping sites and other specialized search services. ${ }^{53}$

17. The upshot is that Google's dominant market share in general search must be evaluated in light of the narrowness of the market definition. To Google's dismay, the agency declined to determine market definition by using the standard SSNIP-test, which evaluates a proposed market definition in terms of purchasers' willingness and ability to switch to products outside the defined market when confronted with a "small but significant non-transitory increase in price" by a hypothetical monopolist. If products found outside the proposed market could serve as economic substitutes, the market definition has to be enlarged to include those products. ${ }^{54}$ The process is repeated until economic substitutes can no longer be found outside the defined market. According to DG COMP, the SSNIP-test was unavailable because Google does not charge users directly for general search, so it was pointless to contemplate consumers' reaction to a hypothetical price increase. Nonetheless, in light of negligible or zero switching costs, it is likely indeed that a consumer suddenly confronted with a non-zero price for using Google search would immediately substitute a free alternative search engine. This suggests a broader market definition than what was adopted by the Commission. This would explain Google's appetite for using the SSNIP-test and DG COMP's refusal to do so.

18. Nevertheless, the market definitions relied upon by the Commission overcame Google's objections with a number of well-researched and documented references cited in the decision, and Google has refrained from challenging market definition directly in its arguments on appeal. ${ }^{55}$ However, the issue of the propriety of the market definition remains. It is reasonable to conclude that general search is something different from specialized search, where the former offers results from across the entire Internet, while the latter offers only a limited set of results within a specific subject matter, such as travel or books. ${ }^{56}$ In the not too distant future, however, when general search engines become more proficient at eliminating the need for specialized searches, this could

53 See Recitals 285-315, that also rebuts Google claim of users utilizing several competing search engines, known as multi-homing, and that "Competition Is One Click Away"as often articulated by Google. For a critical analysis of whether Google is dominant, see M. Herz (2014). Google Search and the Law on Dominance in the EU: An Assessment of the Compatibility of Current Methodology with Multi-Sided Platforms in Online Search. SSRN, pp. 21-55.

54 See Recitals 242-246. The SNNIP test has found prominence among anti-trust enforcers, but remains, as correctly noted by DG COMP, one among several methods available to approximate the cross-price elasticity of demand for products in a candidate market. For reasons why applying the SNNIP test to Internet markets might be too "complex," see M. A. Salinger \& R. J. Levinson, Economics and the FTC's Google Investigation, 46 Rev. Indus. Org. 25 (2015), pp. 52-53.

55 The appeal in case T-612/17 - Google and Alphabet. O.J. 2017C 369, p. 37, does not specify a challenge to the market definitions. In contrast, Google vigorously disputed the market definitions in the underlying DG COMP decision, see, e.g., case AT.39.740 - Google Search (Shopping), Recitals 235-246.

56 This would be consistent with the evolution of the search engine, see M. A. Salinger \& R. J. Levinson, Economics and the FTC's Google Investigation, 46 Rev. Indus. Org. 25 (2015), pp. 32-42. change, at which point the concept of a Universal Search service, as favored by Google, might be the relevant product market definition. In any case, because users often discover or navigate to specialized search engines by finding them in the generic search results, DG COMP's approach to general searches and comparison shopping as two, linked markets is plausible. ${ }^{57}$

19. On the other hand, comparison shopping might more accurately be characterized as a substitute service that competes in the same market as specialized search and merchant platforms, because it allows users to obtain search results for a specific subject matter. ${ }^{58}$ Alternatively, Google's comparison shopping results could be characterized as an improvement on general search services, since it contains content from specialized search sites and merchant platforms and displays it directly next to the generic results. ${ }^{59}$ Such convergence is likely to intensify as the development of the artificial intelligence behind search engines evolves through succeeding generations. ${ }^{60}$ Given numerous, equally plausible approaches, the appropriate market definition for the antitrust analysis may be broader, or different, than the market definitions adopted by DG COMP.

20. More generally, the line between comparison shopping services and shopping sites is unclear because they share many of the same functions. The decision does not make clear, at least from an outside perspective, how DG COMP distinguishes between them ${ }^{61}$ except, perhaps, that only the latter offer direct purchase functionality. ${ }^{62} \mathrm{~A}$ further question is whether social media such as Facebook differs materially from general search when it offers a service that has the same characteristics as general search by incorporating Bing, Microsoft's competing general search engine. ${ }^{63}$ Presumably, these questions will be debated when the decision is reviewed. Although Google may have more or less accepted the maintained market definitions, the eventual emergence of a broader set of market definitions cannot be ruled out, so it is premature to consider the market definition question settled.

57 See Recitals 540-541.

58 This appears to be Google's position, which regards comparison shopping services and merchant platforms to be in the same market, see Case AT.39.740 - Google Search (Shopping), Recitals 227-246 and 590.

59 For a critical analysis of the markets involved, including the segregation of search services into two separate markets, see S. Broos and J. Marcos Ramos, Google, Google Shopping and Amazon: The Importance of Competing Business Models and Two-Sided Intermediaries in Defining Relevant Markets (November 27, 2015). The Antitrust Bulletin, Vol. 62, Issue 2 (2017). Available at SSRN: https://ssrn.com/abstract $=2696045$.

60 See, e.g. M. A. Salinger \& R. J. Levinson, Economics and the FTC's Google Investigation, 46 Rev. Indus. Org. 25 (2015), pp. 32-42.

61 Some of the ambiguity follows from DG COMP having found that Google comparison shopping services only offer links to Google comparison shopping sites, see, e.g., Recitals 411 and 414, making it difficult to distinguish them. Moreover, Google Shopping and Google'Shopping Units, are different but share similar names. DG COMP adds to the confusion by using different names for the same functionality within the same context, e.g., Product Universal (Recital 408) and Shopping Unit (Recital 412).

62 See Recital 240. But see Recital 241, accepting that some comparison shopping services also allow this.

63 See Recital 180. For completes it should be noted that Recital 181 explains how the volume of general searches performed on social network is limited and thus cannot be a direct challenge to providers of general search. 


\subsection{The antitrust theory advanced by DG COMP}

21. The separate market definitions chosen for the analysis are essential to the legal theory advanced in the Google Search (Shopping) decision. At its core, the violation is monopoly leveraging. The decision maintains that dominance in the first (monopolized) general search market may be abused by leveraging that strong market position into the second (competitive) comparison shopping market. The theory depends on the presumption that these markets are separate from one another and also from the specialized search and shopping site markets. Google's presumed motive is not only to secure control of a new and potentially more profitable market, but also to prevent operators of comparison shopping sites from gaining sufficient commercial momentum to threaten Google's dominance in general search. ${ }^{64}$ This can occur if comparison shopping services attain a critical mass of end users that, with sufficiently strong network effects, could create the conditions for a competitive challenge to Google's dominance in general search.

22. The implication is that Google has the incentive to foreclose rival comparison shopping site operators from attaining too large a share of the comparison shopping market. While such a motive is reportedly evidenced by internal Google documents, the decision offers little explicit discussion of the plausibility of such a market threat-and-response. The reasoning makes sense only if one accepts the maintained market definitions and that comparison shopping is a separate market. But, at the same time, the two markets must be close enough in proximity to make a migration by end users from one to the other commercially plausible. More fulsome references to Google's internal documents on this point, ${ }^{65}$ or on external economic studies confirming that the strategy is likely to have actually governed Google's behavior, would have supported such a conclusion. However, the weakness of the decision in this regard is legally irrelevant because abuse of dominance does not require a showing of malicious intent. ${ }^{66} \mathrm{DG}$ COMP is under no obligation to demonstrate the commercial motives for the alleged wrongdoing, although doing so unquestionably would have helped to justify and rationalize the outcome.

23. Although abuse does not require a showing of malicious intent, it does require (i) impairment of competition, and, (ii) a legal breach of the relevant legal standards. Herein lies the second weakness of the EU's Google Search decision. Of the 124 pages of text devoted to the question of abuse, most of it is devoted to explaining

\footnotetext{
64 See Recitals 641-643.

65 There are references in Recitals $381,382,390$ and 643 to internal documents that might indicate that Google was aware of the effects of its conduct, and thus could imply a modicum of wrongful intent, but the issue of intent was not expressly addressed. See note 37, supra, and accompanying text.

66 Cf. case 6/72 - Continental Can, para. 27 and 29; case T-128/98 - Aéroports de Paris, para. 170 and case C-549/10P - Tomra, para. 19-22, cited in case AT.39.740 - Google Search (Shopping), Recital 338
}

how Google's behavior is detrimental to competition —or, more accurately, detrimental to Google's competitorswhile only 11 pages avert to some kind of explanation of how the challenged conduct contravenes the relevant legal standards. ${ }^{67}$ As noted earlier, the challenged conduct consists of downgrading competing services by (i) submitting rival services only to the generic search ranking algorithm, (ii) reserving the best positions in the generic search results and the separate boxes for Google-affiliated offerings, and (iii) coupling the later with pictures and graphics, while presenting competing offerings with only text. ${ }^{68}$ Explaining why this amounts to abuse, DG COMP states: "The Conduct is abusive because it constitutes a practice falling outside the scope of competition on the merits as it: ( $i$ ) diverts traffic in the sense that it decreases traffic from Google's general search results pages to competing comparison shopping services and increases traffic from Google's general search results pages to Google's own comparison shopping service; and (ii) is capable of having, or likely to have, anti-competitive effects in the national markets for comparison shopping services and general search services." ${ }^{69}$

24. It appears that DG COMP does not object to the application of a self-correcting search algorithm, nor directing traffic to Google properties, but only that Google's own offerings are not filtered through the same algorithm, so they are allotted more favorable display positions and presentations, amounting to discrimination by Google in a potentially exclusionary manner. Notably, to make out a prima facie case of abuse, DG COMP does not require a showing that specific competitors were actually excluded from the market or that a certain percentage of the market is foreclosed to them, as long as gradual foreclosure is plausible in the longer term. ${ }^{70}$

25. The decision may comport with the Commission's theory of abusive leverage, but it does little to account for how consumers may be harmed. Comparison shopping is clearly a profitable activity, so it is logical that Google would attempt to divert traffic to its own sites, a fact that does not elude DG COMP, ${ }^{71}$ which recognizes that in a two-sided market losses on one side of the market can be recouped on the other. ${ }^{72}$ The appearance of the Shopping Unit inside separate boxes as an innovation that obviates the need for a second search for a specialized search engine is consistent with this dynamic and presumably

\footnotetext{
67 See Recitals 331-339, 591-607 and 641-652.

68 See Recitals 379, 395-397 and 512. However, Recital 2 seems to single out more favorable display as abusive in itself without the other elements.

69 Recital 341. The abusive conduct and its effect are outlined in Recitals 341-396 and summarized in Recitals 397-401. Further, notable comments on the review of the conduct are offered in Recitals 336, 537 and 661-662.

70 Recital 602. See also Recitals 444-451, which outlines the importance of user traffic to competing comparison shopping service and thus why foreclosure might in the long-run be a plausible result of search bias. See also Recitals 539-588, outlining why the lost traffic cannot be recouped by other instruments, for example, by acquiring adwords or direct traffic.

71 See, e.g., Recitals $157-160$. For completeness it should be noted that general searches might not entail an economic loss. Recital 642 indicates that it may be rather profitable.

72 Moreover, as advertisers presumably are sensitive to the accuracy of search results, any bias would have an adverse effect on the markets for advertising mitigating Google's ability to exercise market power. This also applies directly to users and the generic search results.
} 
beneficial to consumers. ${ }^{73}$ Google has denied directing traffic, but, setting that aside, Google's behavior might be commercially rational and even necessary to develop and maintain the superiority of its general search algorithm. ${ }^{74}$ Since only one service can be displayed in the box, Google's choice is logical. This places considerable stress on the concept of abuse, since the decision implies that competing offerings must be displayed no less prominently than those who pay to be displayed. ${ }^{75}$

26. Naturally, it is unrealistic to accept that operating search engines is unprofitable and implausible that Google's corporate behavior is guided by altruism. Users pay for general search in the form of consumer-generated data that contributes to the development Google's search algorithm, its digital assets, and other Google services, some of which are profitable. ${ }^{76}$ In this context, the essential question is not whether Google diverted traffic, but rather whether such diversion constitutes an abuse, which DG COMP has clearly answered in the affirmative. $^{77}$

\subsection{Evaluating the theory of harm advanced by DG COMP}

27. As we noted, it is debatable whether DG COMP's decision is justified on the basis of the open and novel legal standards they appeared to have relied upon. Because Google was not found to have denied services, Google's conduct was not a refusal to deal, ${ }^{78}$ which would otherwise have been a logical choice, as it would have allowed DG COMP to condemn Google for giving its own services a higher rank in search results, even as a matter of self-preservation. An ineluctable feature of a search engine is that only one link can be first in the results. Few would find it entirely unfair to reserve that position for one's own services, unless somehow the position amounts to an essential facility, in which case there is at least a theoretical basis on which to require some form of non-discriminatory access.

73 See, e.g., Recitals 403-404 for instances in which Google advances the Shopping Unit and blended, Universal search results as innovations beneficial to consumers. DG COMP did not ignore this argument, but did deny its relevance. See also Recital 652 (the case law does not provide for more lenient treatment of product design improvements); and Recital 343 (Google did not invent comparison shopping sites).

74 See Recitals 502-510 and case T-612/17 - Google and Alphabet. 0.J. 2017C 369, p. 37, plea 1,2 and 3

75 Moreover, embedded in DG COMP's reasoning is that Google is operating not only a twosided platform, but also in a two-sided market, which might be less obvious. See G. Luchetta, Is the Google platform a two-sided market?, Journal of Competition Law \& Economics, Vol. 10, Issue 1, 1 March 2014, pp. 185-207.

76 See Recitals 158-159. Admittedly, such "payments" are more or less voluntary, since endusers can still access most of Google's most popular services even if they opt-out of providing data to the company.

77 It appears that a German court applying the same rules has declined to define this selffavoritism as abusive, while a UK court, in principle, was inclined to condemn the behavior, but found no abuse because the behavior had a legitimate business purpose and had little, if any, anticompetitive effect. See District Court of Hamburg ruling of 4/4-2013 in Verband against Google ref: 408 HKO 36/13 and Streetmap v. Google [2016] EWHC 253 at para. 60, $139,161,175$ and 177

78 See Recital 650 . On the limited ability to advance the case under a theory of harm based on a refusal to supply, see P. Akman, The Theory of Abuse in Google Search: A Positive and Normative Assessment Under EU Competition Law, J. L. Tech. \& Policy 2017, pp. 344-355.
28. Alternatively, the matter could have been advanced as a tying case, in which Google's search engine is alleged to be tied with other Google offerings, such as Google Shopping (through the Shopping Unit), with rival alternatives demoted in an anticompetitive manner. ${ }^{79}$ Such a tying theory has a factual basis on the record and includes a coherent theory of consumer harm. In this vein, DG COMP articulates how Google's own comparison shopping services (Google Shopping) often utilizes content from, or links to, Google Product Shopping, instead of undertaking an actual search, and the results are presented as an integrated service by virtue of their appearance in the box. ${ }^{80}$

29. Neither of these theories - refusal to deal or tying - or the anticompetitive harm that flows from them, are relied upon expressly by DG COMP. Moreover, even though the description of the offenses sounds in exclusionary (vertical) discrimination, those words are never used. ${ }^{81}$ Indeed, the decision makes no reference at all to any Article 102(c) jurisprudence that would recognize discrimination as an abuse. The cases cited interpret the general principles of Article 102, not Article 102(c), and hold generally that abuse (i) is an open concept based on the totality of the circumstances, (ii) can involve more than one market, (iii) does not require specific intent, (iv) does not require actual foreclosure (potential foreclosure is sufficient), and, (v) can be rebutted if objectively justified (although no such rebuttal was raised in the Google case). ${ }^{82}$ Of course, case law develops through the inclusion of new principles and the standards relating to discrimination are particularly underdeveloped. More importantly, however, if any conduct by a dominant undertaking that results in potential foreclosure of competitors is to be an abuse, it behooves DG COMP to make clear whether it is so by virtue of a breach of an established standard or a new one, in which case some additional and more compelling evidence of anticompetitive harm should certainly be required.

30. To be sure, voluminous calculations and graphic evidence were offered in support of the claim that Google's algorithm is biased in a way that moves traffic away from competing comparison shopping sites and toward Google's own properties. ${ }^{83}$ But these are difficult to evaluate from the outside. ${ }^{84}$ There does appear to be

\footnotetext{
79 See, e.g., Recital 420, where DG COMP notes how the Shopping Unit and Google's standalone shopping websites are presented as a single service or experience, and thus tied. For a skeptical view of the tying theory, see P. Akman. The Theory of Abuse in Google Search: A Positive and Normative Assessment Under EU Competition Law, J. L. Tech. \& Policy 2017, pp. 307-327.

80 Recitals 411,414 and 420.

81 The closest instance of such a formulation is found in Recital 336, which notes it is abusive to "apply dissimilar conditions to equivalent transactions with other trading parties." For more on discrimination as a basis for the alleged abuse, see E. Aguilera Valdivia, The Scope of the "Special Responsibility" upon Vertically Integrated Dominant Firms after the Google Sopping Case: Is There a Duty to Treat Rivals Equally and Refrain from Favouring Own Related Business?, World Competition 41, No. 1 (2018), pp. 43-68.

82 See Recitals 331-340, 602 and 606 .

83 See, e.g. Recitals $361-370,454-501$ and 539-567 for examples of the statistical and graphic analysis used to support DG COMP's claims.

84 Google has challenged DG COMP's calculations and methodology, see Recitals 619-626.
} 
support for a finding of anticompetitive harm, therefore, at least with respect to the propriety of the market definitions and the correctness of the inferences drawn from the statistical evidence. It is also notable that DG COMP found that Google (i) only allows competing comparison shopping services to appear as generic search results and (ii) applies the ranking quality algorithms to rival sites, while Google's own comparison shopping service is prominently positioned, either in separate box or above or among the first generic search results, supplemented with images, without being subject to being demoted by the algorithm. ${ }^{85}$ It is claimed that Google is aware of these effects, including how its own comparison shopping service would be significantly demoted if subjected to the same ranking quality algorithms and the positive effect of the use of images. ${ }^{86}$ That is, Google allegedly is intentionally undertaking these initiatives for the purpose of significantly increasing traffic to its own Google shopping service. For DG COMP to have advanced a theory of harm stemming the discriminatory effect of this kind of conduct would have been logical, but the Commission chose not to avail itself of the opportunity. ${ }^{87}$

31. DG COMP customarily confines itself to standards of abuse firmly rooted in practice and theory, moving outside of its comfort zone only when necessary in cases of clear-cut anticompetitive practices, preferably coupled with evident malicious intent. Accordingly, doctrinal questions about the legal basis of the Google Search decision abound. Conceivably, a finding of anticompetitive harm could be supported by the evidence adduced, but the presence of malicious intent is less obvious. ${ }^{88}$ More troubling is that the evidence of competitive harm seems to be established only by appealing to a substantial body of dense statistical analysis of the "visibility" and other metrics related to the presentation and display of unaffiliated shopping sites between 2010 and 2016. ${ }^{89}$

32. By declining to link the basis of the decision to welldefined standards of abuse in the Google Search decision, DG COMP has arrogated to itself overly broad discretion to proclaim almost any conduct by an arguably dominant undertaking to be an abuse, without having to meet any predefined legal requirements or even acknowledge awareness of having circumvented established standards. This is evident from the reasoning of the decision, which is based entirely on allegedly biased search results with a supposedly discriminatory effect, but otherwise lacks objectivity. But the case was not advanced as such, either

\footnotetext{
85 Recitals 344 and 379-396 (application of the ranking quality algorithms), and 397-401 (display of comparison shopping services).

86 Recitals $382-386$ and 491.

87 On the limitations of a discriminatory theory of harm see P. Akman, The Theory of Abuse in Google Search: A Positive and Normative Assessment Under EU Competition Law, J. L. Tech. \& Policy 2017, pp. 327-355.

88 See Recitals $381-390$ and 643 , citing internal documents indicating that Google was aware of the effects of its conduct, implying an element of intent. But see note 37, supra, and accompanying text.

89 See Recitals $361-370$ and $454-501$.
}

because DG COMP would have had to acknowledge that the concept of discriminatory abuse remains as yet unsettled and therefore difficult to apply in practice or because the search results might not be as discriminatory or biased as the complainants had alleged. ${ }^{90}$ Throughout the case, Google had denied any bias in its search results, attributing any observed variations in traffic and search patterns solely to the technical design and implementation of its algorithm. To the extent this is true, Google's behavior in search would seem to fall far short of being discriminatory, despite evidence of suspicious traffic patterns. If there is no malicious intent or intentional bias, as Google claims, the entire case ends up standing for the proposition that any conduct by a dominant undertaking is potentially abusive if (i) harm to competition can be shown, (ii) it involves an element of self-favoritism and (iii), there is a likelihood of market foreclosure in longer run that cannot be rebutted.

33. Unfortunately, such a legal rule would widen the applicability of Article 102 and arrogate to DG COMP overly broad discretion to pursue a wide range of conduct in future proceedings, raising the specter of a flood of even less well-founded cases in the future. It is also problematic if the Google Search decision means that DG COMP and the courts will miss the opportunity to develop more clearly defined standards of abuse based on discrimination and self-dealing in a case in which the facts are well suited for just that purpose.

34. Finally, the consumer welfare effects are underexamined and under-explained. Essentially, DG COMP has chosen a "consumer choice" standard, by aligning consumer welfare with maximizing short-term options for alternatives to Google's offering. ${ }^{91}$ However, from an end-user perspective, the boxes and Universal Search are clearly innovations that negate the need for additional searches and, thus, likely to be consumer welfare-enhancing, undermining DG COMP's notion of consumer harm.

\subsection{The issues on appeal of the EU Google Search decision}

35. Clearly, the General Court will have to consider numerous issues when it reviews the EU's Google Search decision, not only the analytical weaknesses and inconsistencies discussed above but also some of the procedural irregularities in the proceedings. ${ }^{92}$ For example, DG COMP will likely have to defend its failure to record a meeting with the complainants in the case, in apparent reliance on the now overturned

\footnotetext{
90 On the limitations of applying existing standards of abuse, see P. Akman, The Theory of Abuse in Google Search: A Positive and Normative Assessment Under EU Competition Law, J. L. Tech. \& Policy 2017, pp. 301-374.

91 For speculation that the consumer choice paradigm may have been considered and rejected by the U.S. Federal Trade Commission in its earlier investigation of Google search, see note 146 , infra, and accompanying text.

92 See Recitals 106-144, outlining the alleged irregularities, including DG COMP's failure to assess the evidence correctly or to take minutes from a meeting and explain adequately its preliminary conclusions, the required remedies, and why it decided to issue fines after
} substantial discussions on a settlement. 
Intel decision, which had suggested that such a lapse is immaterial. ${ }^{93}$ The Intel decision was overturned two months after the EU Google Search decision was announced. By overturning Intel, the Court of Justice has reinforced the obligation to record all such discussions.

36. Equally noteworthy is the fact that the enormous fine levied by DG COMP is based on a novel and untested legal theory of harm imposed after having attempted on several occasions to resolve the matter with behavioral commitments alone. ${ }^{94}$ Furthermore, DG COMP seemed to carefully avoid specifying precisely how Google should remedy its abuse, confining itself instead to ordering that the conduct be terminated and requiring Google to submit evidence of compliance within 90 days of the decision or face daily penalties of up to $5 \%$ of global group turnover. ${ }^{95}$ Clearly, DG COMP had little appetite for setting out how Google should terminate the abuse, which is perhaps understandable in light of the many open issues remaining in the case. ${ }^{96}$ Nevertheless, Google has been thereby left somewhat in limbo and to some extent at the mercy of the complainants, because DG COMP is likely to turn to them for assistance in evaluating any remedial steps that Google may propose to take.

37. This has certain strategic implications. First, in our view, the concept of abuse should be reserved for situations where alternative conduct is or would have been available to the dominant undertaking and can be fashioned as an enforcement remedy, at least in broad terms. The antitrust laws can give clearer signals to business as to what conduct is lawful and what is not. Secondly, whether the abuse has been stopped as ordered should be objectively verifiable under any remedy fashioned by the Commission, otherwise DG COMP will have condemned itself to making an arbitrary assessment that would be almost impossible to impartially review.

38. Lastly, the lack of clarity over how to terminate the infringement calls into question exactly what conduct DG COMP in its Google Search decision has established as abusive conduct, which remains an open question. DG COMP simply states in its opening passages that: "[t]he Decision establishes that the more favorable positioning and display by Google, in its general search results pages, of its own comparison shopping service compared to competing comparison shopping services (the 'Conduct') infringes Article 102." 97

\footnotetext{
93 See Recital 120, referring to case T-286/09 - Intel, Recital 619. Overturned by C- 413/14P -Intel, Recital 93.

94 For a critical analysis see M. Eben, Fining Google: a missed opportunity for legal certainty? European Competition Journal, DOI 10.1080/17441056.2018.1460973 (2018).

95 See Recital 700, summarizing the obligations and P. Akman, The Theory of Abuse in Google Search:A Positive and Normative Assessment Under EU Competition Law, J.L.Tech \& Policy 2017, pp. 365-370 for an analysis of the challenges of meeting them.

96 For an analysis of the remedy, see B. Vesterdorf and K. Fountoukakos, An Appraisal of the Remedy in the Commission's Google Search (Shopping). Decision and a Guide to its Interpretation in Light of an Analytical Reading of the Case Law, Journal of European Competition Law \& Practice, Vol. 9, No. 1 (2018), pp. 3-18.

97 Recital 2.
}

39. Thus, reserving a better display position, rather than the downgrading the display positions of competing offerings, is identified as the abuse. However, the Recitals in the decision that outline the effect of downgrading rivals' links suggest that the abuse really arises on account of both effects, although the extent the Recitals are intended to define the abusive conduct remains unclear. ${ }^{98}$ It is likely that DG COMP will have to defend this ambiguity before the General Court, by clarifying precisely the conduct it found to be abuse, how the conduct harms consumers, and why all of this is sufficiently evident to warrant a record fine.

\section{The U.S. Google Search decision}

40. In September 2011, the Chairman of the U.S. Senate Subcommittee on Antitrust, Competition Policy and Consumer Rights urged the U.S. Federal Trade Commission ("FTC") to investigate Google for misconduct in its search activities. ${ }^{99} \mathrm{~A}$ formal investigation followed in the first half of 2012 into whether Google's conduct amounted to a violation of Section 5 of the Federal Trade Commission Act, which declares "[u]nfair methods of competition (...) and unfair or deceptive acts or practices (...) unlawful." 100 The investigation focused on three concerns: (i) whether Google gave preferential placement to its own content while demoting competitors' content, (ii) whether Google used data obtained without compensation from third party websites, a practice called "scraping," and, (iii) whether Google imposed contractual restrictions on AdWords for the purpose of foreclosing its advertisers' use of other search engines. ${ }^{101}$

98 See, e.g., Recitals 342,344 and 345-377, where the later outlines the demotion. In addition, Recital 512 rebuts the notion that the finding of abuse is limited to better positioning.

99 Letter from Senators Herb Kohl and Mike Lee to Jonathan D. Liebowitz, December 19, 2011, p. 5 .

10015 U.S.C. $\$ 45(\mathrm{a})(1)$. Whenever the Commission has reason to believe that such a violation has occurred, the agency may bring an administrative complaint to compel the violator to cease and desist, with the outcome of the ensuing administrative trial appealable to a U.S. Circuit Court. 15 U.S.C. $\$ 45$ (b). Alternatively, the FTC may commence a civil action in a U.S. district court. 15 U.S.C. $\$ 45(\mathrm{~m})$. The substantive scope of Section 5 is a matter of continuing controversy. A restrictive view maintains that Section 5 is substantively coextensive with the boundaries of Sections 1 and 2 of the Sherman Act, 15 U.S.C. $\S \S 1,2$, and offers only an alternative procedural device by which to enforce the antitrust laws. A more expansive view maintains that Congress would not have enacted Section 5 unless it intended the statute to cover conduct outside the boundaries of the Sherman and Clayton Acts. By analyzing Google's conduct mostly under the standards of Section 2 of the Sherman Act, 15 U.S.C. $\$ 2$, however, the Commission largely side-steps that controversy. But see Separate Statement of Comm'r Roach, discussing the implications of proceeding under Section 5 of the FTC Act rather than under the Commission's authority to enforce the Sherman Act.

101 According to FTC Memorandum dated August 8, 2012 on Google Inc, File No. 111-0163, p. 102 there appears to have been a fourth concern involving exclusivity around AdSense, which was raised in the FTC memorandum, but not in the later press statements. However, the Concurring and Dissenting Statement of Commissioner J. Thomas Rosch Regarding Google's Search Practices, In re Google Inc., FTC File No. 111-0163 January 3, 2012, p. 4 suggests that such exclusivity was potentially a misunderstanding of the facts. 
41. In January 2013, the FTC terminated its investigation ${ }^{102}$ without filing a complaint against Google for alleged search bias, but it did extract from Google voluntary commitments to agree for a period of five years to allow rival websites to prevent Google from scraping and displaying their content and to remove Google's restrictions on the use of its AdWords advertising platform, which had the effect of obstructing the ability of its advertisers to coordinate online campaigns across multiple platforms and search engines. ${ }^{103}$

42. While the FTC's decision may have been something of a close call, it stands as a unanimous decision by all five Commissioners based a fulsome record. The Commission concludes that Google's manner of operating its general search service involved neither an unfair method of competition nor an unfair or deceptive act or practice. In its closing statement, the Commission described a comprehensive investigation into the search bias allegations and alluded to its review of over nine million pages of documents from Google and other parties, from interviews with numerous industry participants and various consumer and advocacy organizations. ${ }^{104}$ The Commission's staff also conducted comprehensive empirical analyses to evaluate the impact of Google's design changes on search engine traffic and user clickthrough behavior. These studies were performed in cooperation with the staffs of five state attorneys general, each conducting parallel and contemporaneous investigations into Google's search practices.

43. From a distance, the FTC decision appears to have been the result of a consensus of a group of sophisticated antitrust enforcement agencies that took account of a comprehensive set of analytical considerations to reach conclusions supported by the evidence and consistent with rigorous economic analysis. But the FTC's closing statement was a mere four pages, so the Commission's reasoning is difficult to analyze in any real depth. Former FTC Chairman Bill Kovacic recently called the FTC's failure to release the reasoning behind its closed investigation of Google "highly frustrating." 105

44. As it happens, however, an internal FTC memorandum, every other page of which was accidentally released to the public, provides support for the notion that the Commission regarded Google's conduct as detrimental to the interests of consumers and that it tends to impede innovation in the online search and advertising

102 Statement of the Federal Trade Commission Regarding Google's Search Practices, In re Google Inc., FTC File Number 111-0163 January 3, 2013.

103 The commitments were submitted to FTC in the form of letter from Google to FCT dated December 27, 2012.

104 Statement of the Federal Trade Commission Regarding Google's Search Practices, In re Google Inc., FTC File Number 111-0163 January 3, 2013, p. 1 .

105 "Kovacic calls for transparency in FTC Google decision," GCRI (February 22, 2018), available at: https://globalcompetitionreview.com/article/1159332/ kovacic-calls-for-transparency-in-ftc-google-decision. markets. ${ }^{106}$ The memorandum also described real and substantial harm to Google's competitors. According to press reports, there was evidence in the record that Google intentionally and deliberately biased its search results, in contradiction to the conclusion reached in the FTC's closing statement. ${ }^{107}$

\section{Overview of the U.S. search bias case}

45. We do know that the FTC's investigation was narrowly focused on the rankings of the websites displayed in general search results, which, as in the EU proceeding but using different nomenclature, the Commission recognized could be provided by two different kinds of search engines. ${ }^{108}$ "Horizontal," or general purpose, search engines, such as Google, attempt to cover the Internet as completely as possible. Specialized, or "vertical," search engines focus on narrowly defined categories of content, such as shopping or travel. The Commission recognized that, although specialized search engines might appear to offer a different kind of service, they also offer consumers an alternative means of searching the Internet for specific categories of information. ${ }^{109}$ In particular, once Google introduced its Universal service, which displays vertical search results in response to a general search query, general search began to function as a true alternative to specialized searches, thereby further mitigating any real, market difference between them.

46. The FTC's search bias investigation evaluated two categories of potential misconduct, ${ }^{110}$ (i) the prominent display of Google-affiliated services in a separate box in response to a general search query, and, (ii) the design or alteration of Google's search algorithm to demote the ranking of certain non-affiliated vertical websites so they appear further down the search results page. Thus, the FTC had to determine whether changes in Google's search algorithm had the purpose of excluding actual or potential competition or instead were intended to improve the quality of its search results and the overall quality of its users' experience. After an intense review of an apparently substantial evidentiary record, the FTC concluded that changes and adjustments in Google's search algorithm were adopted to improve the quality of its search results, so to the extent a negative impact on actual or potential competitors may have been observed, the effect was incidental to a legitimate business purpose. "Although at points in time various vertical websites have experienced demotions," the Commission said, "we find

106 FTC Memorandum dated August 8, 2012 on Google Inc, File No. 111-0163. See B. Mullins, R. Winkler and B. Kendall, Inside the U.S. Antitrust Probe of Google, Wall Street Journal March 19, 2015 for further on the process that led to the release on the FTC document.

107 See B. Mullins, R. Winkler and B. Kendall, Inside the U.S. Antitrust Probe of Google, Wall Street Journal March 19, 2015.

108 Statement of the Federal Trade Commission Regarding Google's Search Practices In the Matter of Google Inc., FTC File Number 111-0163 January 3, 2013, p. 1.

109 Id.

110 Id. at 2 . 
that this was a consequence of algorithm changes that also could plausibly be viewed as an improvement in the overall quality of Google's search results."111

47. In essence, the FTC concluded that the loss of traffic by some of Google's rivals was not the byproduct of anticompetitive conduct but the outcome of "competition on the merits," so Google's behavior was not amenable to condemnation by the antitrust laws. Moreover, Google also voluntarily committed to allow providers of websites to opt out of certain of Google's search offerings without being removed completely and to remove restrictions on the use of its online advertising platform.

\section{The merits of the U.S. search bias case and its outcome}

48. The closing statement clearly reflects an abiding conviction that the evidence in the record suggested that the demotion of the links of Google's rivals, who may have lost sales as a result, was an unintentional consequence of the improvement of Google's algorithm and its general search product. Moreover, Google introduced evidence that it had tested the effect of its Universal search feature before launching it and was apparently willing to tolerate the demotion of some of its own content to less prominent positions in the general search results when a higher ranking would have adversely affected the user experience. The FTC's decision, therefore, seemed to rest upon three related elements: (i) that Google might have disadvantaged its rivals and harmed competition, but, (ii) it was an unintentional consequence of a genuine desire to enhance their consumers' experiences, and, (iii) there was no apparent bias or self-favoritism, as Google's own services were also subject to demotions in rank.

49. Admittedly, the Commission's published closing statement states no such concise explication of the basis of its decision, but on closer inspection of the internal memorandum (or, at least what is available of it) offer a more complicated story.

50. The memorandum shows that the staff regarded scraping and the use of exclusionary arrangements as potential violations of the anti-monopolization provision in Section 2 of the Sherman Act, but it did not view the allegations of search bias in the same light. ${ }^{112}$ This was in spite of evidence that Google engaged in self-favoritism and deliberately biased search results and that Google's Universal search services benefitted competitively from exclusive rights to certain images, from failing to disclose Google affiliations, from excusing itself from the usual "click-through rate" ranking criteria, and from better positioning its services in the generic search results. ${ }^{13}$ Demoting rival sites, moreover, even may have involved

\footnotetext{
111 Id. at 4 .

112 FTC Memorandum dated August 8, 2012 on Google Inc, File No. 111-0163, at 86, 94, 102 and 112 .

113 Id. at $24-26$
}

the sacrifice of short-term profits, ${ }^{114}$ because it depressed revenue from paid advertising. ${ }^{115}$ Between July 2007 and July 2008, self-favoritism by Google in that time elevated Google's specialized Google Product Search from a page rank of seventh to number one, at the expense, of course, of competing services. ${ }^{116}$

51. None of this, however, was apparently enough to support the bringing of a case against Google for allegedly biased and self-serving search results. The incompleteness of the leaked memorandum is particularly unfortunate in that it deprives us of a full understanding of the FTC's assessment of Google's self-favoritism. It is clear that the FTC viewed Google in 2012 as dominant in general search, with a $71 \%$ market share. But it is deeply engrained in U.S. monopolization law that the mere possession of monopoly power is not unlawful unless it is accompanied by an element of anticompetitive conduct. ${ }^{117}$ In contrast to the EU and many other jurisdictions that recognize an offense of abuse of monopoly, current U.S. law does not consider it unlawful to "exploit" a monopoly, so long as the monopoly in question has not been gained, or is not being maintained or expanded, in an unlawful way.

52. The staff clearly had mixed feelings about moving forward on Section 2 monopolization grounds and even compiled a compendium of perceived litigation risks, including questions about whether Google's monopoly power was durable ("an increasing number of websites (e.g., Facebook, Twitter) compet[e] for user time and advertiser dollars"), whether Universal search was a "product improvement" that benefitted consumers, and whether there really lacked sufficient competitive choice in the advertising market (" $[\mathrm{t}]$ he largest advertisers (...) already advertise on both [Google's] AdWords and [Microsoft's] AdCenter"). ${ }^{118}$

\section{Could the FTC have prevailed in a case against Google search based on the record evidence adduced in the EU case?}

53. Had the Commission chosen instead to proceed against Google search, might they have prevailed in court, given the evidence developed in the EU proceeding?

\footnotetext{
114 The so-called "profit sacrifice test" as indicative of exclusionary conduct is based on the substantive economic notion that firms will not pursue strategies that involve a shortrun loss unless they view those losses as an investment in future profitability. See, e.g., run loss unless they view those losses as an investment in future profitability. See, e.g.,
A. D. Melamed, Exclusive Dealing Agreements and Other Exclusionary Conduct-Are There Unifying Principles? 73 Antitrust L.J. 375, 389-90 (2006). For reasons why such a test may be inapplicable to the Google search case, see, e.g., J. M. Jacobson and S. A. Sher, "No Economic Sense"Makes No Sense for Exclusive Dealing, 73 Antitrust L.J. 779 (2006).

115 It should be noted that Google did not charge merchants for the privilege of being listed in the Universal search services when the FTC issued its decision.

116 FTC Memorandum dated August 8, 2012 on Google Inc, File No. 111-0163, p. 30

117 Verizon Commc'ns. v. Law Offices of Curtis V. Trinko, 540 U.S. 398, 407 (2004); see also United States v. Grinnell Corp., 384 U.S. 563, 570-571 (1966) and United States v. Int'l Harvester, 274 U.S. 693, 753-54 (1927) (same).

118 FTC Memorandum dated August 8, 2012 on Google Inc, File No. 111-0163, pp. 84-86 and 114 .
} 
Recall that the EU's Google Search decision rested upon four principal conclusions:

- First, comparison shopping services, and other sources that feed into the box are separate products, and thus specialized search and general search occupy different defined markets. The EU did not consider the Universal feature to be an improvement to general search, as did the FTC, and even if it had, EU doctrine does not provide for more favorable assessment of such innovations when they lead to potential foreclosure in adjacent markets. ${ }^{119}$

- Second, self-favoritism in the form of better positioning in the generic search results, exclusive display in the box, and the evaluation of Google's own links under a different, more lenient quality ranking algorithm, is abusive, if doing so impedes competitors and their position in the market.

- Third, DG COMP is not required to prove that the self-favoritism has the actual effect of foreclosing specific competitors, nor that a certain percentage of the market has been foreclosed. It is sufficient if foreclosure might occur in the long-run. ${ }^{120}$ Moreover, the absolute number of remaining active rival comparison shopping services is not probative of whether abuse has occurred, as the number and economic strength of market rivals might have been higher but for the self-favoritism; and,

- Fourth, although it is possible for a dominant undertaking to defend its behavior as either objectively necessary or counterbalanced by efficiency gains that also benefit consumers, this was not found to apply in this case. ${ }^{121}$

54. Aside from the somewhat different views of market definition held by the two agencies, the cases are practically identical with respect to the conduct complained of. The differences in the names of the services involved in the DG COMP and the FTC cases, e.g., Universal Search, Product Universal, the "box," and Shopping Units, are trivial, because they all refer to the same specialized information about Google products and services provided automatically in response to a general search inquiry in a box appearing next to or above the generic search results. Even the alleged bias appears identical in the two cases, involving (i) reserving the boxes for Google offerings and (ii) applying the ranking algorithm solely to competing offerings, although only DG COMP viewed this as part of a deliberate strategy of foreclosure, rejecting the notion that the boxes were an innovate improvement to general search.

119 Case AT.39.740 - Google Search (Shopping), Recital 652.

120 Case AT.39.740 - Google Search (Shopping), Recitals 602-603.

121 Case AT.39.740 - Google Search (Shopping), Recitals 340 and 653-671.
55. Tempting as it may be to attribute the different outcomes in the two jurisdictions to the disparate views of the relevant markets and the EU's rejection of the boxes as a product improvement, those explanations for the FTC having closed its investigation are probably incomplete. For one thing, at points the Commission seemed to accept separate market definitions for vertical specialized search engines and general search, ${ }^{122}$ although it made no direct finding to that effect. ${ }^{123}$ Yet, paradoxically, the Commission also seemed to regard Universal search services as an improvement to general search results. In any case, the staff ultimately regarded Google's selffavoritism as non-cognizable under existing Section 2 jurisprudence, while the EU adjudged the same conduct as a violation of Article 102.

56. The question facing the Commission, however, was not only whether Google's conduct violated Section 2, but also whether the company violated Section 5 of the FTC Act. ${ }^{124}$ As a technical matter, the FTC's statutory authority to challenge anticompetitive conduct is always based on Section 5. Aside from Section 5, the agency has no independent legal authority to bring cases for violations of the antitrust laws, including the Sherman Act. To be sure, an overwhelming majority of cases against "unfair methods of competition" are alleged and pleaded as violations of the Sherman or Clayton Acts, but in such cases the Commission invokes its Section 5 authority and incorporates Sherman or Clayton Act law and principles by reference.

57. Thus, the question of whether the Commission should or could have brought a case to court based on Google search bias involves really two questions: i) whether the FTC could or should have brought a Sherman Act, Section 2 case (under its Section 5 authority), and ii) whether it could or should have brought a free-standing or independent Section 5 claim.

\subsection{The prospective Section 2 case}

58. The Commission's staff in its memorandum clearly considered itself constrained by current Section 2 case law, which is generally unreceptive to condemning bare self-favoritism. At the same time, the pro-competitive justifications presented by Google appeared plausible and persuasive. Although much of the staff's reasoning can be assumed to appear on the missing pages, there is enough material available to indicate that the Commission

\footnotetext{
122 FTC Memorandum dated August 8, 2012 on Google Inc, File No. 111-0163, pp. 64-74.

123 The issue is discussed by Richard J. Gilbert, U.S. Federal Trade Commission Investigation of Google Search (2013), in The Antitrust Revolution (J. E. Kwoka, Jr. \& L. J. White eds., Oxford Univ. Press 7th ed. forthcoming), pp. 9-10 ("A necessary condition for an alleged Oxford Univ. Press 7 th ed. forthcoming), pp. $9-10$ ("A necessary condition for an alleged
vertical service to be a separate market is sufficient differentiation from general purpose search engines. It is unclear whether online comparison shopping services such as Nextag or Shopzilla are sufficiently differentiated from general-purpose search engines to meet this condition particularly with the evolution of Universal Search displays that blur the distinction between general-purpose search results and specialized vertical services"). Moreover, the FTC's closing statement also refers to specialized (vertical) searches as separate from general (horizontal) searches. Statement of the Federal Trade Commission Regarding Google's Search Practices In the Matter of Google Inc., FTC File Number 111-0163 January 3, 2013, p. 1

12415 U.S.C. $\$ 45(\mathrm{a})(1)$ (“Unfair methods of competition in or affecting commerce, and unfair or deceptive acts or practices in or affecting commerce, are hereby declared unlawful").
} 
accepted the genuineness of the desire by Google to continuously innovate and produce high quality search results, albeit blended with a desire to direct users to its own services to increase its own revenue.

59. These blended effects led the staff to trace the weakness of a prospective Section 2 case against Google for search bias to the need for balancing, in which the pro-competitive effects of Universal search as a product improvement with substantial benefits to its users would have to be weighed against the anticompetitive effect the conduct appeared to inflict on the vertical search market. "The evidence," the memorandum stated: "paints a complex portrait of a company working toward an overall goal of maintaining its market share by providing the best user experience, while simultaneously engaging in tactics that resulted in harm to many vertical competitors, and likely helped to entrench Google's monopoly power over search and search advertising." 125

60. Given that these countervailing factors would need "extensive balancing, a task," the staff noted, "that courts have been unwilling - in similar circumstances-to perform under Section 2," the ultimate conclusion was a recommendation against moving forward with an action based on the search bias allegations. ${ }^{126}$

61. Although the prospect of having to perform such balancing may have been unappealing, the decision not to proceed against Google search probably did not turn on any serious doctrinal objections on the part of the FTC's staff to balancing anticompetitive effects against claimed efficiencies, which has long been a feature of Section 2 jurisprudence, or on the view that courts are loath to engage in such an analysis. It is more plausible that the decision was driven by the specter of having to balance the specific anti- and pro-competitive effects raised in the case in the context of a new and perhaps not-fully-understood digital industrial environment.

62. Some concept of balancing has marked U.S. Section 2 jurisprudence since at least the 1911 Standard Oil decision, which adopted the rule of reason to Section 2 cases. ${ }^{127}$ The Supreme Court reaffirmed the same approach in Lorain Journal v. United States ${ }^{128}$ and Aspen Skiing Co. v. Aspen Highlands Skiing Corp,${ }^{129}$ while, more recently, the D.C. Circuit in Microsoft described in detail precisely how such balancing is to be performed when it becomes necessary to determine the line between "vigorous competition" on the one hand and "illicit exclusion" on the other. ${ }^{130}$
63. The Microsoft court adopted a structured approach to Section 2 litigation that involves a series of burdenshifting steps, beginning with a demonstration by the plaintiff that the monopolist's conduct has the requisite anticompetitive effect to make out a prima facie case. After such a showing, the plaintiff wins, unless the defendant asserts a procompetitive justification, i.e., " a non-pretextual claim that its conduct is indeed a form of competition on the merits because it involves, for example, greater efficiency or enhanced consumer appeal." ${ }^{131}$ In that case, the burden shifts back to the plaintiff to rebut the procompetitive justification by rebutting, for example, that there are cost savings, efficiencies, or enhancements that benefit consumers. In the event that the plaintiff is unable to entirely rebut the procompetitive assertion, so there is a residual anticompetitive effect with some modicum of enhanced consumer appeal or increased efficiency, the plaintiff may still win, if it "demonstrate[s] that the anticompetitive harm of the conduct outweighs the procompetitive benefit." 132

64. In practice, however, the judicial exercise in which anticompetitive effects are weighed against procompetitive effects remains controversial. There is even some doubt over whether such a procedure can be found in nature. "Indeed," Professor Gavil writes, "despite nearly a century of devotion to the 'balancing' concept, in fact there is a remarkable dearth of examples of courts actually engaging in any kind of balancing." ${ }^{.33}$ Litigated cases in which a court has had to balance whether there is sufficient evidence of anticompetitive effect against whether there is sufficient evidence to support the business efficiencies claimed by the defendant are rare. More typically, once a court has accepted the plaintiff's prima facie case, the defendant's claimed efficiencies are usually either accepted, in which case the defendant wins, or they are found to be pretextual and invalid, in which case the plaintiff wins.

65. Other criticisms of the balancing approach are that it fails to provide sufficient guidance as to what constitutes lawful business conduct, or that it is inherently asymmetrical in favor of the plaintiff, because it pits merely theoretical anticompetitive effects against what must be proven as efficiencies, or, alternatively, in favor of defendants, because the evidence of efficiencies is solely in the possession of the defendants. Nonetheless, three FTC Commissioners in 2008 expressly supported the Microsoft approach as a general test for monopolizing conduct. $^{134}$
125 FTC Memorandum dated August 8, 2012 on Google Inc, File No. 111-0163, p. 86

126 Id.

127 Standard Oil v. United States, 221 U.S. 1 (1911).

128342 U.S. $143(1951)$

129472 U.S. $585(1985)$

130 United States v. Microsoft Corp., 253 F.3d 34, 58 (D.C. Cir. 2001).
131253 F.3d at 59 (D.C. Cir. 2001).

132 Id.

133 A. I. Gavil, Exclusionary Distribution Strategies by Dominant Firms: Striking a Better Balance, 72 Antitrust L.J. No. 1 (2004), p. 73.

134 Statement of FTC Commissioners Harbor, Liebowitz, and Rosch on the Issuance of the Section 2 Report by the Department of Justice 1 (Sept. 8, 2008); see also 2010 Horizontal Merger Guidelines, $§ 10$ (expressly adopting structured approach to Clayton Act Section 7 merger cases). 
66. Moreover, such balancing frequently features prominently in the evaluations of proposed mergers that are routinely undertaken by the FTC, the Antitrust Division, and, if a complaint is filed, the courts. In the 2010 FTC/DOJ Horizontal Merger Guidelines, the U.S. agencies appeared to adopt a "sliding scale" approach to balancing (at least in the context of merger control) under which cognizable efficiencies that have been verified and do not arise from anticompetitive reductions in output or service potentially may reverse or reduce a merger's anticompetitive harm. But the 2010 Guidelines seem to balance such efficiencies against anticompetitive harm on a sliding scale, stating: "In conducting this analysis, the Agencies will not simply compare the magnitude of the cognizable efficiencies with the magnitude of the likely harm to competition absent the efficiencies. The greater the potential adverse competitive effect of a merger, the greater must be the cognizable efficiencies, and the more they must be passed through to customers, for the Agencies to conclude that the merger will not have an anticompetitive effect in the relevant market. When the potential adverse competitive effect of a merger is likely to be particularly substantial, extraordinarily great cognizable efficiencies would be necessary to prevent the merger from being anticompetitive." 135

67. Some observers maintain that the approach to balancing anti- and pro-competitive effects in the Guidelines requires the parties to overcome a greater burden of proof on efficiencies than does the Commission in satisfying its prima facie burden of establishing anticompetitive effects. For example, former Commissioner Joshua D. Wright's dissent to the FTC's 2014 decision to issue a Complaint against the Ardagh Group's proposed acquisition of Saint-Gobain Containers Inc. and Compagnie de Saint-Gobain voiced concern that the Commission had created a burden of proof for efficiencies that was disproportionately high in comparison to the Commission's initial burden. ${ }^{136}$ But, even so, Commissioner Wright did not hesitate to weigh in with his own assessment of the anticompetitive effects of the proposed merger ("I am persuaded that the proposed transaction is likely to generate, at best, small unilateral price effects"137) against his evaluation of the parties' claimed efficiencies ("My own analysis of cognizable efficiencies in this matter indicates they are significant" ${ }^{138}$ ).

68. It is unlikely, therefore, that the Commission did not attempt to prove a Section 2 violation against Google search because the balancing procedure itself is inherently objectionable or disfavored by the courts, as the staff suggested in its memorandum. It is more likely that the procedure as applied to the particular facts of the case - weighing the loss of vertical search providers

\footnotetext{
135 FTC/DOJ Horizontal Merger Guidelines (2010), at 31.

136 Dissenting Statement of Commissioner Joshua D. Wright, In the Matter of Ardagh Group S.A., and Saint-Gobain Containers, Inc., and Compagnie de Saint-Gobain, FTC File No. 131-0087 (April 11, 2014).

137 Id. at 2.
}

138 Id. at 5 . against the appearance of the arguably efficient and useful boxes in Google's general search results-would be simply too arbitrary, standard-less, or intractable to justify the attempt to secure a favorable judicial decision. In contrast to the ambiguity of whether general and specialized search are separate markets, which may have been a weakness deterring the Commission from attempting to prove up a Section 2 case, the staff may have anticipated that the need to eventually reckon between the exclusion of vertical search rivals on the one hand and Google's efficiency arguments on the other would bedevil any court confronted with a Section 2 complaint.

\subsection{The prospective Section 5 case}

69. Congress enacted the FTC Act in 1914 (two weeks before it passed the Clayton Act) to upgrade the U.S. system of competition law that had been in place since 1890, in part by endowing the FTC with Section 5 authority to reach conduct not necessarily proscribed by the other U.S. competition statutes. ${ }^{139}$ In a "pure" or "standalone" Section 5 case, the Commission challenges conduct beyond the Sherman Act's limits under the theory that that conduct, whether or not it constitutes a violation of the Sherman Act, constitutes an "unfair method of competition." Could the Commission have mounted a successful standalone case under Section 5? Or, put differently, did Google's conduct involve the kind of behavior that lies outside the boundaries of the Sherman Act but nonetheless deserved condemnation under the unfairness doctrine?

70. The answer depends critically on the standards applicable to Section 5. Some commentators from the business community assume that, by definition, a standalone Section 5 action departs from the consumer welfare standard and the essential public policy behind the U.S. antitrust laws in favor of a rudderless, ad hoc characterization of conduct that is somehow "unfair." 140 Under such a view, the complainants are likely to consider Google's unfairness to be self-evident, even if it means a preordained outcome against Google based on little more than governmental fiat.

71. But, such Section 5 jeremiads, in our view, go too far, and the conception of Section 5 as necessarily a rudderless ship ignores both the Commission's historical reluctance to invoke its standalone Section 5 authority as well as the set of clearly stated principles released by the FTC on August 13, 2015, which lists the Commission's

139 W. E. Kovacic \& M. Winerman, Competition Policy and the Application of Section 5 of the Federal Trade Commission Act, 76 Antitrust $L . J$. No. 3 (2010). The authors cite FTC v. Texaco, Inc., 393 U.S. 223 (1968), in which the oil company, Texaco, had entered into commission arrangements with manufacturers of tires, batteries, and accessories, and then pressured its Texaco-branded dealers to sell those manufacturers'products. Finding that Texaco "holds dominant economic power over its dealers," the Supreme Court affirmed the FTC's decision to use Section 5 to condemn Texaco's conduct. Id. at 231; see also FTC v. Sperry \& Hutchinson Trading Stamp Co., 405 U.S. 233 (1972) (Commission could use its Section 5 authority to reach practices outside the letter and spirit of the Sherman and Clayton Acts under the so-called “unfairness doctrine.")

140 See, e.g., G. Manne and B. Szoka, Section 5 of the FTC Act and monopolization cases: A brief primer, in Truth on the Market, available at: https://laweconcenter.org/resource/ section-5-of-the-ftc-act-and-monopolization-cases-a-brief-primer. 
desiderata for standalone enforcement of Section 5. ${ }^{141}$ In its statement of principles, the Commission described three conditions for the Commission to challenge an act or practice as an unfair method of competition on a standalone basis.

72. First, the Commission will be guided by the public policy underlying the antitrust laws, namely, the promotion of consumer welfare, according to which a pure Section 5 case would not necessarily require abandoning the consumer welfare standard. ${ }^{142}$ This principle largely dispenses with the notion that such cases will inevitably be decided on the basis of ad hoc or subjective notions of "unfairness," by tethering Section 5 tightly to the welfare analysis at the heart of the present-day Sherman Act.

73. The second FTC Section 5 enforcement principle requires that "the act or practice challenged by the Commission must cause, or be likely to cause, harm to competition or the competitive process, taking into account any associated cognizable efficiencies and business justifications." 143

74. The third and final Section 5 enforcement principle is that "the Commission is less likely to challenge an act or practice as an unfair method of competition on a standalone basis if enforcement of the Sherman or Clayton Act is sufficient to address the competitive harm arising from the act or practice." Thus, pure Section 5 authority should only be invoked against conduct beyond the reach of the Sherman or Clayton Acts.

75. Depending on how the FTC goes about applying them, such principles can constrain the territory beyond the Sherman and Clayton Acts that can be occupied by Section 5. By adopting a similar set of enforcement norms in the Google search bias case, the Commission's staff may have perceived the same kinds of difficulties with proceeding solely under Section 5 as with pursuing a case under Section 2. For example, the second principle to account for "cognizable efficiencies and business justifications" would have led to the same kind of balancing exercise the staff was eager to avoid in a Section 2 case. ${ }^{144}$ Similarly, the second principle could require the Commission to particularize precisely how Google's conduct interferes with the competitive process, a task made difficult by the fact that the "but for" or "undistorted" competitive process that would have taken place in the absence of the challenged conduct is far from obvious.

141 U.S. Federal Trade Commission, Statement of Enforcement Principles Regarding "Unfair Methods of Competition”Under Section 5 of the FTC Act, August 13, 2015.

142 Id.

143 Supra note 141

144 Section 5(n) of the FTC Act in 1994 also limits the Commission's authority to bring Section 5 enforcement actions"unless the act or practice causes or is likely to cause substantial injury to consumers which is not reasonably avoidable by consumers themselves and not outweighed by countervailing benefits to consumers or to competition."15 U.S.C. $\$ 45(\mathrm{n})$.
76. But a strict focus on consumer welfare - and all the baggage accumulated in U.S. antitrust cases that implement the consumer welfare standard-may have been the FTC's real stumbling block in a pure Section 5 proceeding against Google. If so, it would explain a great deal of the difference between the law applied by the FTC in the U.S. and DG COMP in the EU and largely account for the dramatically different outcomes.

77. The precise wording of the first principle is that "the Commission will be guided by the public policy underlying the antitrust laws, namely, the promotion of consumer welfare." The implementation of the consumer welfare standard in U.S. antitrust has come to require assessment of productive, allocative, and dynamic efficiencies. In the context of the Google search bias case, the burden of showing a net reduction in consumer welfare could be impossible to satisfy. Google would certainly have been able to show an increase in output during the period of the supposed violation and the FTC would be hard pressed to demonstrate an increase in prices. ${ }^{145}$ Moreover, the Commission's apparent concession that Google's boxes represent a beneficial innovation would favor Google in a court's assessment of dynamic efficiency. In short, if the Commission interpreted the public policy underlying Section 5 to be to promote consumer welfare, then proof of negative welfare effects according to the standards applied by the courts in traditional Sherman Act cases would also be required in a pure Section 5 case, a significantly better litigation option than proceeding with a monopolization claim under Section 2.

78. A pure Section 5 case against Google search becomes more feasible as the interpretation the policy to promote consumer welfare is broadened to encompass theories of anticompetitive harm evidenced by something other than standard antitrust welfare economics. A broader concept of harm to consumers would admit evidence, for example, of conduct that creates an obstacle or retardant to the competitive process or disrupts the normal pace or flow of commerce. ${ }^{146}$ The underlying assumption of such an approach is that consumers gain from the process of market competition, so that acts or practices that interfere with the process necessarily deprive consumers of those benefits. In a similar vein, the consumer choice approach focuses on actual or potential choice in the marketplace and the key factors necessary for markets to function competitively. ${ }^{147}$

79. At the same time, the farther from traditional welfare analysis the Commission strays in its application of its standalone Section 5 authority, the less likely its case will

145 It may have been possible to demonstrate a price effect on the advertising side of Google's search platform, but the inquiry did not extend to those markets.

146 See, e.g., E. M. Fox, What Is Harm to Competition? Exclusionary Practices and Anticompetitive Effect, 70 Antitrust L. $J$. No. 2 (2002), pp. 371-372 (describing "the analysis of mergers and dominant firm conduct that may be exclusionary but do not necessarily change the shapes of the triangles and rectangles, at least not in knowable ways," in which "[t]he analyst looks at the market structure and dynamics, and asks whether the practice interferes with and degrades the market mechanism").

147 See, e.g., R. H. Lande, Consumer Choice as the Ultimate Goal of Antitrust, 62 U. Pitt. L. Rev. No. 3 (2001), pp. 503-525. 
ultimately succeed. As one of us cautioned in 2012, an unbounded Section 5 case against Google search will never be sustained by a reviewing court. To the contrary, "the only way a court will allow the FTC to pursue a pure Section 5 theory against Google would be if the agency constrains itself with a coherent principle of competitive $\operatorname{harm}(\ldots) .{ }^{\prime 148}$

80. The consumer choice framework would have been feasible for the Commission because it addresses non-price issues that consumers care about, such as variety, quality, privacy, and innovation, but at the same time it is constrained by limiting principles. For example, only conduct that significantly and materially impairs consumer choice, or significantly distorts consumers' ability freely to choose among the alternatives the market provides, would count. Thus, not every decrease in choice would qualify as an injury to competition. More choice is not always necessarily good, because too much choice can lead to consumer confusion and higher search or transaction costs. The purpose of the consumer choice standard is to eliminate practices that artificially restrict the choices the free market would have otherwise provided. "[E]very antitrust violation reduces consumer choice, but not every reduction in consumer choice is an antitrust violation," 149 so a better label for the framework might be the "optimal consumer choice" standard.

81. Although such an approach is likely to be resisted in some quarters of the U.S. antitrust establishment, ${ }^{150}$ it fits squarely into the "ordoliberal school" supposedly governing EU competition law and apparently at play in DG COMP's Google Search (Shopping) decision. ${ }^{151}$ To reach the result it did, DG COMP must have been guided to some extent by the notion of intervening against anticompetitive conduct so as to maintain the competitive process and protect the emergence of market outcomes unmolested by a dominant market participant. These same indicia of anticompetitive conduct are endorsed, within limitations, by the consumer choice framework. If, at the time of the investigation into Google search the consensus of the FTC staff was that the consumer choice framework departed too widely from an underlying policy to promote consumer welfare, many of the same obstacles to bringing a Sherman Act case also would have disqualified a pure Section 5 case.

148 R. H. Lande \& J. L. Rubin, How the FTC Could Beat Google, CPI Antitrust Chronicle, (1) October 2012, at ${ }^{*} 2$ (recommending the consumer choice framework as the standard to be applied in a pure Section 5 case against Google search).

149 Id. at $* 3$.

150 See, e.g., J. D. Wright \& D. H. Ginsburg, The Goals of Antitrust: Welfare Trumps Choice, 81 Ford. L. Rev. (2013), p. 2406.

151 P. Behrens, The Ordoliberal Concept of 'Abuse' of a Dominant Position and its Impact on Article 102 TFEU (September 9, 2015) in Nihoul/Takahashi, Abuse Regulation in Competition Law, Proceedings of the 10th ASCOLA Conference, Tokyo (2015), available at SSRN: https://ssrn.com/abstract=2658045, at ${ }^{*} 24$ ("Ordoliberals have always appreciated and highlighted the positive welfare effects of competition in terms of productive, allocative and dynamic efficiencies. What they refuse, however, is to measure the allocative and dynamic efficiency effects of individual business strategies. The determination and materialization of these effects depends on consumers' choice in the market [which] can only be the result of effective competition. These results cannot be specified ex ante, because that would require access to the full amount of information which competition is supposed to discover in the first place").
82. But the Commission's Statement of Enforcement Principles regarding the unfair competition prong of Section 5 codifying the policy of promoting consumer welfare was issued a full three years after the FTC's Google search non-prosecution decision. Thus, the Commission's staff might very well have examined the case through the lens of the consumer choice framework and still decided that Google's conduct neither significantly restricted the choices available to consumers nor significantly distorted consumers' ability freely to choose among the alternatives the market provided. However, as long as both agencies continue to obscure the precise legal standards on which their decisions rest, it will remain unclear whether the different outcomes are attributable to the application of different legal standards defining anticompetitive conduct or to similar standards that have been differently applied.

83. Nonetheless, even under a consumer choice framework, it may have been difficult for the Commission to have attempted to proceed to court with a pure Section 5 case without the ability to quantify in some meaningful way how consumers actually using these services have been constrained by the appearance of boxes in search results or disadvantaged by the disappearance or weakening of a number of specialized search engine websites. Thus, any Section 5 case might have presented challenges that the Commission may have considered at the time to be, if not overwhelming, at least overly risky.

\section{Conclusion}

84. Despite the focus of both the FTC and DG COMP on self-favoritism in which only Google-affiliated services are displayed in the side boxes and specialized and general searches are blended, the FTC declined to prosecute, while DG COMP viewed this as anticompetitive conduct in defiance of the special responsibility of dominant undertakings. DG COMP's Google Search decision has engendered considerable debate, because neither the U-turn from a non-monetary settlement to the biggest fine in Commission history nor the grounds for the market definitions nor the theory of anticompetitive harm are fully explained. But the FTC's earlier closing statement to explain its decision not to proceed was similarly uninformative. The Commission's closing statement alluded to the competitive issues in a general way but failed to specify whether the legal standard applied to Google's conduct in its consideration of a pure Section 5 claim departed in any meaningful way from the customary standards of Section 2 and, if so, whether Google's conduct failed to amount to a violation even under such a wider set of anticompetitive indicia. It is not evident, in other words, that the FTC was compelled to close its case without identifying an antitrust violation, particularly in light of the description of anticompetitive behavior in the leaked memorandum.

85. The similarities between the two cases are considerable. The market definitions utilized by DG COMP echo many of the same concerns voiced by the FTC, so it is conceivable that the FTC could have drawn a sharper 
boundary between specialized and general search, where the latter is dominated by Google. Similarly, the FTC's apparent acceptance of comparison shopping as an improvement to general search rather than as a separate market could have been an artifact of a less comprehensive study of the relevant data or the relatively broader scope of the FTC's investigation. The FTC had investigated multiple examples of self-favoritism and alleged search bias, whereas DG COMP confined itself to comparison shopping services, potentially making the risk of foreclosure and harm to consumer choice easier to demonstrate. In slightly different circumstances, therefore, the FTC might have ended up with market definitions substantively identical to DG COMP.

86. We attribute the difference in the two outcomes despite these similarities to three principal factors working in conjunction. First and foremost, DG COMP did not appear to consider itself particularly constrained by established case law or the existing legal standards of single-firm abuse. Confronted with a form of selffavoritism by Google that affected competition, DG COMP appeared to decide to expand the concept of abuse, presumably after concluding that the behavior would have eluded other theories, such as discrimination. This maneuver imparts a sense of regulatory shopping, in which the legal standard to be applied to alleged abuse depends on the facts of the case, resulting in this instance on an emphasis on the effects of the conduct on consumer choice and speculation over the dominant undertaking's malicious intent. By contrast, the FTC appears to have been cautious about moving beyond the customary consumer welfare standard of Section 2 by having chosen, for example, not to bring a standalone Section 5 case, in which it could have implemented a broader notion of consumer welfare, such as the consumer choice framework.

87. It remains to be seen whether the more inclusive ordoliberal legal standard for abuse of dominance that we infer to have been applied in the EU's Google Search decision is a one-off occurrence or instead prefigures a more significant departure by Europe's competition authorities from the current post-Chicago trans-Atlantic consensus. Outside of the Google Search decision, transAtlantic competition policy and enforcement priorities continue to converge on legal standards informed by U.S.-style welfare economics. The upcoming decision of the General Court, as well as the other Google cases (Android and AdSense), are all opportunities for greater clarity into the EU's legal standards for abuse and how issues of consumer harm and harm to competition ought to be adjudicated.

88. The second factor influencing the differing outcomes is that the economic analysis of the alleged anticompetitive effects appears to have been more developed in DG COMP's decision than in the FTC's deliberations. The DG COMP decision is rich in statistical graphs and tables demonstrating impediments to competition, whereas a similar level of analytical detail is absent from the internal FTC staff memorandum, if not from the deliberations as a whole. ${ }^{152}$ Moreover, with its narrower focus, DG COMP could have had a simpler story of anticompetitive harm to substantiate through economic evidence.

89. Third, the FTC, in contrast to DG COMP, was clearly more receptive to Google's claims regarding dynamic efficiency and its positioning of Universal and the boxes as innovations that benefit end users. Thus, the consumer welfare effects and Google's claimed countervailing efficiencies were given greater weight by the FTC, even though DG COMP acknowledged that Google's innovations benefit consumers, at least in the short term. Only a few pages of DG COMP's decision were devoted to consumer harm and the prospect of counterbalancing efficiencies. The FTC appears to have deliberated the matter far more extensively, if for no other reason than because it would have had to convince a court had it chosen to proceed.

90. Google's appeal of DG COMP's decision to the General Court will provide further insight into the case and its merits. It is notable that DG COMP had no appetite for indicating how Google might have acted differently or could have ended its abuse. The FTC might have taken this into account in anticipation of its burden before a court. Although antitrust in the EU and the U.S. are two separate sets of rules with separate ancestral lineages, the fundamentally different evaluation of otherwise identical facts indicates some potential lacunas in DG COMP's reasoning and calls into question its lack of openness. While the EU's case will eventually be settled, the underlying fundamentals will persist on both sides of the Atlantic. The legacy left by the Google search cases may be one of open-ended choices and missed opportunities to fashion potentially more effective approaches to reckoning with consumer harm and welfare in the digital age. 
Concurrences est une revue trimestrielle couvrant l'ensemble des questions de droits de l'Union européenne et interne de la concurrence. Les analyses de fond sont effectuées sous forme d'articles doctrinaux, de notes de synthèse ou de tableaux jurisprudentiels L'actualité jurisprudentielle et législative est couverte par onze chroniques thématiques.

\section{Editoriaux}

Jacques Attali, Elie Cohen, Claus-Dieter Ehlermann, Jean Pisani Ferry, Ian Forrester, Eleanor Fox, Douglas H. Ginsburg, Laurence Idot, Frédéric Jenny, Arnaud Montebourg, Mario Monti, Gilbert Parleani, Jacques Steenbergen, Margrethe Vestager, Bo Vesterdorf, Denis Waelbroeck,

Marc van der Woude.

\section{Interviews}

Sir Christopher Bellamy, Lord David Currie, Thierry Dahan, Jean-Louis Debré, Isabelle de Silva, François Fillon, John Fingleton, Renata B. Hesse, François Hollande, William Kovacic, Neelie Kroes, Christine Lagarde, Johannes Laitenberger, Emmanuel Macron, Robert Mahnke, Ségolène Royal, Nicolas Sarkozy, Marie-Laure Sauty de Chalon, Tommaso Valletti, Christine Varney...

\section{Dossiers}

Jacques Barrot, Jean-François Bellis, David Bosco, Murielle Chagny, John Connor, Damien Géradin, Assimakis Komninos, Christophe Lemaire, Ioannis Lianos, Pierre Moscovici, Jorge Padilla, Emil Paulis, Robert Saint-Esteben, Jacques Steenbergen, Florian Wagner-von Papp, Richard Whish...

\section{Articles}

Guy Canivet, Emmanuelle Claudel, Emmanuel Combe, Thierry Dahan, Luc Gyselen, Daniel Fasquelle, Barry Hawk, Nathalie Homobono, Laurence Idot, Frédéric Jenny, Bruno Lasserre, Luc Peeperkorn, Anne Perrot, Nicolas Petit, Catherine Prieto, Patrick Rey, Joseph Vogel, Wouter Wils...

\section{Pratiques}

Tableaux jurisprudentiels : Actualité des enquêtes de concurrence, Contentieux indemnitaire des pratiques anticoncurrencielles, Bilan de la pratique des engagements, Droit pénal et concurrence, Legal privilege, Cartel Profiles in the EU...

\section{International}

Belgium, Brésil, Canada, China, Germany, Hong-Kong, India, Japan, Luxembourg, Switzerland, Sweden, USA...

\section{Droit \& économie}

Emmanuel Combe, Philippe Choné,

Laurent Flochel, Frédéric Jenny,

Gildas de Muizon, Jorge Padilla,

Penelope Papandropoulos, Anne Perrot,

Nicolas Petit, Etienne Pfister, Francesco Rosati,

David Sevy, David Spector..

\section{Chroniques \\ ENTENTES}

Ludovic Bernardeau, Anne-Sophie Choné Grimaldi, Michel Debroux, Etienne Thomas

\section{Pratiques unilatérales}

Laurent Binet, Frédéric Marty,

Anne Wachsmann

\section{Pratiques commerciales DÉLOYALES}

Frédéric Buy, Valérie Durand, Jean-Louis Fourgoux, Rodolphe Mesa, Marie-Claude Mitchell

\section{Distribution}

Nicolas Ereseo, Dominique Ferré, Didier Ferrier, Anne-Cécile Martin

\section{CONCENTRations}

Jean-François Bellis, Olivier Billard, Jean-Mathieu Cot, Ianis Girgenson, Sergio Sorinas, David Tayar

\section{Aides D'État}

Jacques Derenne, Bruno Stromsky, Raphaël Vuitton

\section{Procédures}

Pascal Cardonnel, Alexandre Lacresse, Christophe Lemaire

\section{RÉGULATIONS}

Orion Berg, Hubert Delzangles, Emmanuel Guillaume

\section{Mise en COnCURRENCE}

Bertrand du Marais, Arnaud Sée

\section{ACtions Publiques}

Jean-Philippe Kovar, Francesco Martucci, Stéphane Rodrigues

\section{DROITS EUROPÉENS ET ÉTRANGERS}

Walid Chaiehloudj, Sophie-Anne Descoubes, Marianne Faessel, Pierre Kobel, Silvia Pietrini, Jean-Christophe Roda, François Souty, Stéphanie Yon-Courtin

\section{Livres}

Sous la direction de Stéphane Rodrigues

\section{Revues}

Christelle Adjémian, Mathilde Brabant, Emmanuel Frot, Alain Ronzano, Bastien Thomas 


\section{Tarifs 2019}

\section{$>$ Abonnement Concurrences +}

Devis sur demande

Quote upon request

Revue et Bulletin: Versions imprimée (Revue) et électroniques (Revue et Bulletin) (avec accès multipostes pendant 1 an aux archives) Review and Bulletin: Print (Review) and electronic versions (Review and Bulletin)

(unlimited users access for 1 year to archives)

Conférences: Accès aux documents et supports (Concurrences et universités partenaires)

Conferences: Access to all documents and recording (Concurrences and partner universities)

Livres: Accès à tous les e-Books

Books: Access to all e-Books

\section{$>$ Abonnements Basic}

\section{e-Bulletin e-Competitions | e-Bulletin e-Competitions}

$\square$ Version électronique (accès monoposte au dernier $\mathrm{N}^{\circ}$ en ligne pendant 1 an, pas d'accès aux archives)

$785,00 € 942,00 €$ Electronic version (single user access to the latest online issue for 1 year, no access to archives)

\section{Revue Concurrences I Review Concurrences}

$\square$ Version électronique (accès monoposte au dernier $\mathrm{N}^{\circ}$ en ligne pendant 1 an, pas d'accès aux archives) Electronic version (single user access to the latest online issue for 1 year, no access to archives)

\section{Renseignements | Subscriber details}

Prénom-Nom I First name-Name

Courriel I e-mail

Institution I Institution

Rue I Street

Ville I City

Code postal I Zip Code

Pays I Country.

$\mathrm{N}^{\circ}$ TVA intracommunautaire I VAT number $(E U)$

\section{Formulaire à retourner à I Send your order to:}

\section{Institut de droit de la concurrence}

68 rue Amelot - 75011 Paris - France I webmaster@concurrences.com

\section{Conditions générales (extrait) I Subscription information}

Les commandes sont fermes. L'envoi de la Revue et/ou du Bulletin ont lieu dès réception du paiement complet. Consultez les conditions d'utilisation du site sur www.concurrences.com ("Notice légale").

Orders are firm and payments are not refundable. Reception of the Review and on-line access to the Review and/or the Bulletin require full prepayment. For "Terms of use", see www.concurrences.com. 